\section{$\underset{\substack{\text { hommes } \\ \text { \& migrations }}}{ }$}

\section{Hommes \& migrations}

Revue française de référence sur les dynamiques

migratoires

1323 | 2018

Persona grata

\title{
Babels, Exils syriens. Parcours et ancrages (Liban, Turquie, Europe)
}

Lyon, Le Passager clandestin, coll. « Bibliothèque des frontières », 2018, 128 pages, $10 €$

\section{Nihad Jnaid}

\section{(2) OpenEdition}

12 Journals

\section{Édition électronique}

URL : https://journals.openedition.org/hommesmigrations/7954

DOI : 10.4000/hommesmigrations.7954

ISSN : 2262-3353

Éditeur

Musée national de l'histoire de l'immigration

\section{Édition imprimée}

Date de publication : 1 octobre 2018

Pagination : 217-218

ISBN : 978-2-919040-42-1

ISSN : 1142-852X

\section{Référence électronique}

Nihad Jnaid, « Babels, Exils syriens. Parcours et ancrages (Liban, Turquie, Europe) », Hommes \& migrations [En ligne], 1323 | 2018, mis en ligne le 01 octobre 2018, consulté le 08 janvier 2022. URL : http:// journals.openedition.org/hommesmigrations/7954; DOI : https://doi.org/10.4000/ hommesmigrations.7954 


\section{Babels, Exils syriens. Parcours et ancrages (Liban, Turquie, Europe)}

Lyon, Le Passager clandestin, coll. «Bibliothèque des frontières », 2018, 128 pages, $10 €$.

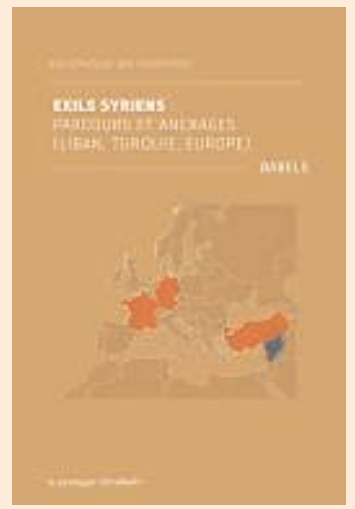

D'une ampleur massive, l'exil syrien est sans doute l'exemple d'une crise majeure à plusieurs titres: pour les réfugiés, en matière de conflit régional, en raison du nombre élevé de déplacés et en termes du traitement de cette crise. Le ton est donné dès l'introduction de l'ouvrage avec cette réflexion d'Edouard Saïd sur l'exil, "une invitation à distinguer les exilés des réfugiés, ainsi que des expatriés et des émigrés». Si le mot «réfugié» a pris une dimension politique avec la nécessité d'une aide internationale urgente aux groupes d'individus désorientés, celui d'«exilé » implique selon lui une "forme de solitude et de spiritualité». La faculté des réfugiés à prendre leur destin en main est délibérément mise en avant dans le livre. D'où la valorisation des différentes initiatives individuelles mais également des diverses configurations d'acteurs œuvrant dans les réseaux d'aide et de coopération. L'ouvrage se concentre sur les réponses à l'exil massif syrien, notamment au Liban. Si le premier chapitre analyse les modalités d'accès aux institutions d'assistance et d'aide aux réfugiés, les autres chapitres se penchent sur les réalités suivantes: les réfugiés syriens au sein des camps palestiniens à Chatila, les réfugiés à de Borj el Barajneh dans Beyrouth et, enfin, l'expérience contrastée des Syriens et des Irakiens à Zgharta. L'exemple du centre social du Borj el Barajneh montre notamment que l'accueil et l'assistance aux réfugiés syriens a permis de reconfigurer la mission des institutions sociales publiques et parfois de les redynamiser grâce à la participation croissante de jeunes Syriens réfugiés aux activités socio-éducatives. Mais tous les quartiers n'offrent pas cet aspect positif. L'ouvrage montre la hiérarchie du traitement des réfugiés, notamment dans le cas de réfugiés syriens-palestiniens. La segmentation de l'aide la plus significative est celle des circuits éducatifs et de la manière dont les enfants réfugiés y sont intégrés. Tandis que les élèves syriens sont accueillis, l'aprèsmidi, dans des sessions qui leur sont exclusivement réservées au sein des écoles publiques, les élèves palestiniens-syriens se trouvent, eux, mélangés avec les élèves palestiniens-libanais dans les écoles de l'Office de secours et de travaux des Nations unies pour les réfugiés de Palestine dans le Proche-Orient (UNRWA). Cette distinction dessine une communauté d'appartenance entre Palestiniens de Syrie et du Liban tout en accentuant la concurrence pour l'accès à l'aide attisant ainsi une «rivalité intercommunautaire». Le voyage comme trajectoire d'opportunité est l'autre forme de différenciation et de fracture entre réfugiés, car ils ne sont pas tous égaux face à cette possibilité. Les Syriens se voient proposer une réinstallation en Europe par l'UNHCR, contrairement aux réfugiés palestiniens qui restent contraints dans leurs déplacements. Dès lors, Beyrouth, et à travers elle le Liban, devient une ville de destination ou de transit. L'implantation d'une 
intelligentsia syrienne en exil au Liban serait massive en raison de la proximité géographique entre les deux pays et de l'intensité des multiples liens qui les unissent. Beyrouth est à la fois une ville de «lutte des places» et une ville "au carrefour d'une nouvelle culture syrienne». Cette nouvelle scène accueille des dynamiques culturelles et où se déploient des projets d'éditions, d'audiovisuels et de création artistique. Si le Liban apparaît comme un élément incontournable du parcours migratoire des Syriens, ce livre aborde aussi la construction internationale des politiques publiques face aux menaces de «laisser les réfugiés partir vers l'Europe».

Nihad Jnaid 